-especially in the matter of cheapness-when he was stopped by the President. The practice Mr. Head follows at meetings of the scientific and technical Societies is not tending to enhance the respect felt for the once honoured name of Siemens. Sir Lowthian Bell said what he said in Paris last year over again. The position he takes up-that no more heat can be got from a pound of fuel than Nature put in it-is perfectly sound, but there is no need to repeat the truism at such great length and so often.

The Sheffield Water Works was the subject of the last paper read at the meeting.

On the whole, it cannot he doubted that the meeting of the Mechanical Engineers at Sheffield was below the average, and badly managed. If Mr. Eaton's paper on the waterworks had been taken as read, and Mr. Addy's contribution on milling cutters had been brought forward, the meeting might have done something to redeem its character as a representative assemblage of Mechanical Engineers. The Catalogue of the Park Gate Iron and Steel Works might also have been taken as read. Both the latter and the water-works paper were acceptable as guides to the respective excursions, but that was no reason why members should be required to sit and listen whilst Mr. Bache read through them at a speed which rendered it quite impossible to follow.

We have not space to refer to the visits to works in Sheffield open to visitors, and indeed there was not much of exceptional interest. Exception must be made, however, to a loom for weaving horse-hair cloth, which was seen at the works of Laycock and Sons. The wonderful ingenuity displayed by designers of textile machinery appears here to have reached its culminating point. Horse-hair has several undesirable features from a textile point of view. The filaments are generally no longer than 3 or 4 feet; though exceptional hairs have been known as long as 6 feet, we believe. The thickness differs considerably at each end; the material is very elastic, and it is so hard that it will speedily wear away the hardest steel over which it may be dragged. In order to overcome these difficulties, the designer of this loom, Mr. W. S. Laycock, has introduced a shuttle with jaws that take hold of each hair as it is presented, and a device which is known as the selector. The latter is a hand-for we can call it nothing less-which picks up one hair, and only one, to present to the jaws of the shuttle. It has to let go at the very instant the shuttle takes hold, otherwise the hair would be dragged through its fingers, which would soon be worn away. Sometimes, however, the fingers fail to grasp this single hair; it must be remembered if it were to take two hairs the cloth would be spoiled. It then makes a second try, and, if the second fail, yet a third. Supposing the third attempt also prove unsuccessful, there being no time to make a fourth, the selector promptly stops the weft motion, so that no change takes place whilst the shuttle is making its traverse without a hair to form the weft. Theophrastus Such, after a visit to a textile factory, had a nightmare, in which mechanism usurped the place of humanity, and became the inexorable master of mankind. The conceit is worked out with much skill, and appears quite plausible when viewed in the light of mechanism which not only performs the most delicate operations, but knows when it misses, tries again as long as trying is of avail, and, if it fail at last, takes steps to prevent mischief following.

\section{ON THE ORIGIN OF THE DEEP TROUGHS OF THE OCEANIC DEPRESSION: ARE ANY OF VOLCANIC ORIGIN?}

THE consideration of the question with regard to the origin of the ocean's deep troughs requires, as the first step, a general review of oceanic topography; for according to recent bathymetric investigations, the deep troughs are part of the system of topography, and its grander part. We need, for this purpose, an accurate map of the depths and heights through all the great area. Such a map will ultimately be made through the combined services of the Hydrographic Departments of the civilized nations. At the present time the lines of soundings over the oceans, especially over the Pacific and Indian, are few, and only some general conclusions are attainable. It is to be noticed that the system of features of the oceanic area are involved in the more general terrestrial system; but since the

'This paper is accompanied in the American Journal of Science from which it is reprinted, by a bathymetric map.

$$
\text { No. } 1084 \text {, VOL. } 42]
$$

former comprises nearly three-fourths of the surface of the sphere, it is not a subordinate part in that system.

With reference to this discussion of the subject $I$ have prepared the accompanying bathymetric map.

\section{The Bathymetric Map, and the General Features} of the OCEanic Depression Displayed by it.

I. The Map.-In the preparation of the bathymetric map I have used the recent charts of the Hydrographic Departments of the United States and Great Britain, ${ }^{1}$ which contain all depths to date, and the lists of new soundings published in German and other geographical journals. In order that the facts on which the bathymetric lines are based may be before the reader a large part of the depths are given, but in an abbreviated form, 10o fathoms being made the unit : 25 signifying 2500 fathoms or nearly (between 2460 and 2550 ); $2 \cdot 3$, about 230 fathoms, 4, about 40 fathoms. Only for some deep points is the depth given in full. The addition of a plus sign $(+)$ signifies no bottom reached by the sounding. ${ }^{2}$

In the plotting of oceanic bathymetric lines from the few lines of soundings that have been made, the doubts which constantly rise have to be settled largely by a reference to the general features of the ocean, and here wide differences in judgmen may exist in the use of the same facts; but through the depths stated on the map, the reader has the means of judging for himself. In the case of an island the lines about it may often have their courses determined by those of adjoining groups, or by its own trend; but in very many cases new soundings are needed for a satisfactory conclusion.

Some divergences on the map from other published bathymetric maps require a word of explanation. The northern half of the North Pacific is made, on other deep-sea maps, part of a great 3000-fathom area (between 3000 and 4000) stretching from the long and deep trough near Japan far enough eastward to include the soundings of 3000 fathoms and over in mid-ocean along the $35^{\text {th }}$ parallel. It has seemed more reasonable, in view of present knowledge from soundings, to confine the deepsea area off Japan to the border-region of the ocean, near the Kurile and Aleutian Islands, and leave the area in mid-ocean to be enlarged as more soundings shall be obtained. Again, in the South Pacific, west of Patagonia, the area of relatively shallow soundings (under 2000 fathoms) extending out from the coast, is on other maps bent southward at its outer western limit so as to include the area of similar soundings on the parallels of $40^{\circ}$ and $50^{\circ}$, between $112^{\circ}$ and $122^{\circ} \mathrm{W}$. The prevailing trends of the ocean are opposed to such a bend, and more soundings are thought to be necessary before adopting it.

It may be added here that in the Antarctic Atlantic, about the parallel of $66 \frac{1}{2}^{\circ} \mathrm{S}$. and the meridian of $13^{\frac{1}{2}} \mathrm{~W}$., a large area of 3000 and 4000 fathoms has been located. It was based, as I have Iearned from the Hydrographic Department of the British Admiralty, on a sounding in 1842 by Captain Ross, R.N., in which the lead ran out 4000 fathoms without finding bottom. The sounding was, therefore, made before the means available were "sufficient to insure the accuracy of such deep casts." 3

2. The Feature-lines of the Oceanic and Bordering Lands.--The courses of island-ranges and coast-lines have a bearing on the question relating to the courses of the deep-sea troughs, and

I I am indebted to the Hydrographic Departments of Great Britain as well as the United States for copies of these charts.

2 On the map the bathymetric lines for ro00, 2000, 3000, and 4000 fathoms, besides being distinguished in the usual way by number of dots, have been made to differ in breadth of line, the deeper being made quite heavy in order to exhibit plainly the positions of the areas without the use of colours. The line for roo fathoms is, as usual, a simple dotted line. As the bathymetric map herewith published is necessarily small, and none of the ordinary maps of the oceans give either deep-sea soundings or a correct idea of the trends of the oceanic ranges of islands, I state here that the charts of the U.S. Hydrographic Department for the Atlantic, Pacific, Indian, and Arctic Oceans may be purchased of dealers in charts in the larger sea-board cities for 50 may be purchased of dealers in charts in there are several large charts to cents a sheet and less according to size. them in New York City is that of each ocean.) One of the firms selling them in New York City is that of T. S. and J. D. Negus, I40 Water Street. The British Admiralty have published a map of the Pacific with its soundings on a single sheet, and for the Atlantic and Indian Oceans with part of the Pacific, besides charts of the Antarctic and Arctic seas. The occasional Bulletins from the Hydrographic Department and Petermann's Mitteilun

new data issued for the perfecting of such a chart. 3 The communication received from the Admiralty Office adds that "Some
of Ross's soundings up to 2660 fathoms have been proved correct, and hence the sounding in $68^{\circ} \mathrm{S}$., referred to, has been retained on our charts until disproved." "Another sounding obtained by Ross in the Atlantic has had strong doubts thrown upon it by a sounding of 3000 fathoms obtained not
very far from its position." See the accompanying map, near latitude $54^{\circ} \mathrm{S}$. 
therefore, by way of introduction, they are here briefly reviewed. ${ }^{1}$ The system of trends in feature-lines takes new significance from a bathymetric map, for the courses are no longer mere trends of islands or emerged mourtain peaks; they are the trends of the great mountain ranges themselves; and, in the Pacific, these mountain courses are those of half a hemisphere. Some of the deductions from such a map are briefly as follows :-

(I) Over the Pacific area there are no prominent rorth-andsouth, or meridional, courses in its ranges, and none over the Atlantic, except the axial range of relatively shallow water in the South Atlantic. And to this statement it may pertinently be added that there are none in the great ranges of Asia and Europe, excepting the Urals; none in North America; none in South A merica, excepting a part of those on its west side.

(2) The ranges in the Pacific Ocean have a mean trend of not far from north-west-by-west, which is the course very nearly of the longer diameter of the ocean. One transverse range crosses the middle South Pacific-the New Zealand-commencing to the south in New Zealand and the islands south of it, with the course N. $35^{\circ} \mathrm{E}$., and continuing through the Kermadec Islands and the Tonga group, the latter trending about N. $\mathbf{2 2}^{\circ}$ $\mathrm{E}$. , and this is the nearest to north and south in the ocean, except toward its western border.

(3) The oceanic ranges are rarely straight, but, instead, change gradually in trend through a large curve or a series of curves. For example, the chain of the central Pacific becomes, to the westward, north-north-west; and the Aleutian range and others off the Asiatic coast make a series of consecutive curves. Curves are the rule rather than the exception. Moreover, the intersections of crossing ranges, curved or not, are in general nearly rectangular.

(4) Approximate parallelisms exist between the distant ranges or feature-lines; as (I) between the trend of the New Zealand range and that of the east coast of North America; and also that of South America (which is continued across the ocean to Scandinavia); also ( $\mathbf{z}$ ) between the trend of the foot of the New Zealand boot with the Louisiade group and New Guinea farther west, and the mean trend of the islands of the central Pacific both south and north of the equator, and also that of the north shore of South America. These are a few examples out of many to be observed on the map.

(5) The relatively shallow-water area which stretches across the North Atlantic from Scandinavia to Greenland-the Scandinavian plateau, as it may well be called-is continued from these high latitude seas south-westward, in the direction of the axis of the North Atlantic (or parallel nearly to the coast of eastern North America and the opposite coast of Africa), and becomes the "Dolphin Shoal."

It may be a correlate fact in the earth's system of features that a Patagonian plateau stretches ont from the Patagonia coast, or from high southern latitudes, in the direction of the longer axis of the Pacific, and embraces the Paumotu and other archipelagos beyond.2

The above review of the earth's physiognomy, if accompanied by a survey of the map, may suffice for the main purpose here in view : to illustrate the general truths-that system in the featurelines is a fact; that the system is world-wide in its scope ; and - since these feature-lines have been successively developed with the progress of geological history-that the system had its foundation in the beginning of the earth's genesis and was developed to full completion with its growth.

\section{Facts Bearing on the Origin of the Deep-sea TROUGHS.}

In treating of this subject, the facts from the vicinity of volcanic lands that favour a volcanic origin are first mentioned;

I This subject of the system in the earth's feature-lines is presented at length, with a map, in my Expedition Geological Report, pp. II-23 and 4I4-424; and also more briefly in the American Journal of Science, II. ii. 381, 1846.

2 As parallelisms may have importance that is not now apparent, I draw attention to one between the Mediterranean Sea that divides Europe from Africa, and the West India (or West Mediterranean) sea that divides North from South America. Both have an eastern, middle, and western deep basin. Their depths (see map) in the East Mediterranean, are 2170,2040 , and 1585 fathoms ; in the West Mediterranean (the three being the Caribbean, th West Caribbean or Cuban, and the Gulf of Mexico), 2804, 3428, and 2080 fathoms. Further, in each Mediterranean Sea, a shallow-water plateau extends from a prominent point on the south side, northward, to island tetween the eastern and middle of the deep basins; one from the north-east angle of Tunis to Sicily, the other from the north-east angle of Honduras to Jamaica and Haiti, the two about the same in range of depth of water. And this last parallelism has its parallels through geological history, even to the Quaternary, when the great Mammals made migrations to the islands in each from the continent to the south. secondly, those from similar regions that are not favourable to such an origin; thirdly, facts from other regions bearing on the question.

\section{A. Facts apparently favouring a Volcanic Origin.}

I. The Pacific soundings have made known the existence of two deep-sea depressions, if not a continuous trough, within forty miles of the Hawaiian Islands; one situated to the northeast of Oahu, or, north of Molokai, with a depth of 3023 fathoms, or 18,069 feet, and the other east of the east point of Hawaii, 2875 fathoms, or within 750 feet of 18 , o0o feet. Again, 450 miles north-east of Oahu, there is a trough in the ocean's bottom, over 800 miles long, which runs nearly parallel with the group and has a depth of 3000 to 3540 fathoms; and, as far south, another similar trough of probably greater length has afforded soundings of 3000 to 3100 fathoms. The depths about the more western part of the Hawaiian chain of islands have not yet been ascertained, and hence the limits of the deep areas are not known. Such depths, so close to a line of great volcanic mountains, the loftiest of the mountains not yet extinct, appear as if they might have resulted from a subsidence consequent on the volcanic action.

The subsidence might have taken place (I) either from underminings-which the amount of matter thrown out and now constituting the mountain chain, with its peaks of 20,000 to 30,000 feet above the sea-bottom, shows may be large; or (2) from the gravitational pressure in the earth's crust, about a volcanic region which speculation makes a source of the ascensive force and of the upward rising of the lavas, the subsiding crust following down the liquid surface beneath. In either case the mass of ejected material might be a measure more or less perfectly of the maximum amount of subsidence.

2. In the western part of the North Pacific, at the south end of the volcanic group of the Ladrones off the largest island of the group, Guam, the Challenger found a depth of 4475 fathoms, one of the two deepest spots yet known in the Pacific. The situation with reference to the group is like that off the east end of the Hawaiian group.

3. East of Japan and the Kuriles, a region of ranges of volcanoes, there is the longest and deepest trough of the ocean, the length 1800 miles, the depths 4000 to 4650 fathoms; and farther north-east, south of one of the Aleutian Islands, a depth of 4000 fathoms occurs again; and depths of 3100 to 3664 fathoms also still farther east. It is probable that the $4000-$ line trough continues from the Kurile to this deep spot off the Aleutian volcanic range; and if so, the length of the trough is over 2500 miles. The map is made to suggest its extension still farther eastward; but among the very few soundings made, none below 3664 fathoms have yet been obtained off the more eastern Aleutians.

Other similar facts may be found on the map; and stil others may exist which are not now manifest owing to the sinking of oceanic areas and islands. But no cases can be pointed to which are more decisively in favour of volcanic origin.

\section{B. Facts from the Vicinity of Volcanic Regions apparently not referable to a Volcanic Origin.}

The ocean off the western border of North and South America affords striking examples of the absence of deep troughs from the vicinity of regions eminently volcanic. The South American volcanoes are many and lofty; and still the ocean adjoining is mostly between 2000 and 2700 fathoms in depth; and just south of Valparaiso, it shallows to $\mathbf{1 3 2 5}$ fathoms. The only exception yet observed is that of a short trough of 3000 to 3368 fathoms close by the Peruvian shore. It may, however, prove to be a long trough, although certainly stopping short of Valparaiso. The waters, however of the Pacific border of America deepen abruptly compared with those of the Atlantic border; and the significance of this fact deserves consideration.

The facts off Central America are more remarkable than those off the coast to the south. The volcanoes are quite near to the Pacific coast, and still the depths are between 1500 and 2500 fathoms.

The condition is the same off the west coast of North America. Of the two areas of 3000 and over, nearest to the east coast of the North Pacific, one is 600 miles distant in the latitude of San Francisco, and the other is within $10^{\circ}$ of the equator and $20^{\circ}$ of the coast; both too far away to be a consequence of volcanic action in California, Mexico, or Central America. 
In the North Atlantic the European side has its volcanoes, and has had them since the Silurian era, and yet the nonvolcanic North American side of the ocean has far the larger areas of deep water and much greater mean depth. The Azores or Western Islands, which are all volcanic, have depths around them of only 1000 to 2000 fathoms, and no local troughs. Iceland, the land of Hecla, is in still shallower waters, with no evidence of local depressions off its shores. The Canaries are volcanic, but no deep trough is near them.

\section{Facts from Regions not Volcanic which are unfavourable to the idea of a Volcanic Origin.}

I. In the North Pacific, near its centre, the area of 3000 or more fathoms about $35^{\circ} \mathrm{N}$.; the two similar but smaller areas toward its eastern border; the areas north of the Carolines in the western part of the ocean; the broad equatorial area about the Phœnix group; the area in the South Pacific in $170^{\circ} \mathrm{W}$., east of Chatham Island, and another just south of Australia, are all so situated that no reason is apparent for referring them to a volcanic origin. Some of the areas are in the coral island latitudes, and the supposed volcanic basis of coral islands makes a volcanic origin possible, but their probable size and position appears to favour the idea of origin through some more fundamental cause. The area in the South Pacific, east of Chatham Island, is 450 miles distant from the land. The border of southern Australia, abreast of the deep-sea trough, has no known volcano.

2. In the Atlantic, arway from the West Indies. - The 3000fathom areas of the North and South Atlantic-that is, the three in the North Atlantic, the two in the South Atlantic, and the two equatorial, one near the coast of Guinea and the other near that of South America-occupy positions that suggest no relation to volcanic conditions. The Cape Verdes, north of the equator, are partly encircled by one of the deep areas, somewhat like the eastern end of the Hawaiian group; but this bathymetric area appears to be too large to owe its origin directly to volcanic work in the group. The coast of Guinea near the 3000-fathom area has nothing volcanic about it, and the opposite coast of South America, near another, is free from volcanoes.

The only facts in the Atlantic that suggest a volcanic origin are the depression of 2445 fathoms within 40 miles of the west side of the volcanic Cape Verde archipelago, and that of 2060 fathoms within 20 miles of Ascension Island; and a connection is possible.

3. In and near the West Indies. - The most remarkable of the depths of the Atlantic area are situated in and near the region of the West Indies, as is well illustrated and discussed by Mr. Alexander Agassiz in his instructive work on the "Three Cruises of the-Brake." The deepest trough of the ocean, 456I fathoms, occurs within seventy miles of Porto Rico; and yet this island has no great volcanic mountain, though having basaltic rocks. By the north side of the Bahama belt of coral reefs and islands, for 600 miles, as Mr. Agassiz well illustrates, the depth becomes 2700 to 3000 fathoms within twenty miles of the coast-line, and at one point 2990 within twelve miles, a pitch-down of $1: 3.5$; and nothing suggests a volcanic cause for the abrupt descent. Cuba and Hayti are not volcanic, and look as if they were an extension of Florida, so that no grounds exist for assuming that the Bahamas rest on volcanic summits.

One of the strangest of 3000 -fathom troughs is that which commences off the south shore of Eastern Cuba, having there a depth of 3000 to 3180 fathoms. It is within 20 miles of this non-volcanic shore, and nearly three times this distance from Jamaica. No sufficient reason appears at present for pronouncing its origin volcanic. It is continued in a west-by-south direction to a point beyond the meridian of $85^{\circ} \mathrm{W}$., or over 700 miles, making it a very long trough, and the depths vary from 2700 to 3428 fathoms. The depression extends on into the Gulf of Honduras, carrying a depth of 2000 fathoms far toward its head, and in a small indentation of the coast it stops; for nothing of it appears in the outline of the Pacific coast or the depths off it, and nothing in the range of volcanic mountains on the coast. Against the three deepest parts of the trough there are, first, the Grand Cayman Reef, 20 miles north of a spot 3428 fathoms deep; second, banks in $I_{3}$ and $I_{5}$ fathoms within $I_{5}$ miles of a depth of 2982 fathoms ; and third, Swan Island Reef, 15 miles south of a depth of 3010 fathoms; the first of the three indicating a slope to the bottom of $\mathrm{I}: 5$, and the last of $\mathrm{r}: 4.4$. Why these greatest depths in the trough, so abrupt in depression, should be on one side of shoals or emerged coral reefs, it is not easy to explain; and the more so that the part of the trough south of Cuba has nothing volcanic near by in the adjoining mountain range, and the fact also that the westernmost end of the trough extends on for 175 miles, and there has a depth of 3048 fathoms, with 2000 fathoms either side and no coral reefs.

\section{Arrangement of the Deep-sea Troughs in the two halves of the} Oceans, pointing to some other than a Volcanic Origin.

The western half of the Atlantic and Pacific oceans contains much the larger part of the 3000 -fathom areas and all the depths over 4000 fathoms. In the North Atlantic the areas of 3000 and over in the western half, or off the United States, are very large; and the bathymetric line of 2500 fathoms extends westward nearly to the rooo-fathom line. This important feature can be appreciated for both oceans from a look at the map without special explanations.

As a partial consequence of this arrangement, the Pacific, viewed as a whole, may be said to have a westward slope in its bottom, or from the South American coast toward Japan. This westward slope of the bottom exists even in the area between New Zealand and Australia-the ocean in this area being shallow for a long distance out on the east side and deepening to 2500 2700 fathoms close to that non-volcanic land, New South Wales, in eastern Australia. In the Atlantic, the slope is in the direction of its north-east-south-west axis, either side of the Dolphin Shoal, but especially the western side, rather than from east to west, it commencing in the Scandinavian plateau and ending in the great depths adjoining the West Indies.

Owing to the system in the Atlantic topography, the Dolphin Shoal-the site of the Atlantis of ancient and modern fable-is really an appendage to the eastern continent, that is to Europe and is shut off by wide abyssal seas from the lands to the west that have been supposed to need its gravel for rock-making.

But the view that the west half of an oceanic basin is always the deepest becomes checked by finding in the Indian Ocean that the only areas that are 3000 fathoms deep or over are in the eastern part of the ocean and off the north-west coast of Australia, and near western Java and Sumatra. The greatest depths in its western half or toward Africa, are 2400 to 2600 fathoms. ${ }^{1}$

\section{Conclusions.}

I. The facts reviewed lead far away from the idea that volcanic action has been predominant in determining the position of the deep-sea troughs. It has probably occasioned some deep depressions within a score or two of miles of the centre of activity, but beyond this the great depths have probably had some other origin.

2. It is further evident that the deep-sea troughs are not a result of superficial causes of trough-making. Erosion over the ocean's bottom cannot excavate isolated troughs. The coldest water of the ocean stands in the deep holes or troughs instead of running, as the reader of Agassiz's volume has learned.

The superficial operation of weighting the earth's crust with sediment, or with coral or other organic-made limestone, and filling the depressions as fast as made, much appealed to in explanations of subsidence, has not produced the troughs; for filled depressions are not the kind under consideration. Moreover, the areas are out of the reach of continental sediments and too large and deep to come within the range of possibilities of organic sedimentation or accumulation. The existence of the troughs is sufficient proof of this. The deep troughs of the West Indian and adjoining seas are in a region of abundant pelagic and sea-border life, and yet the marvellous depths exist. And the depths of the open oceans are no less without explanation. Those close by the Bahamas, extending down to 16,000 and 18,000 feet, are evidence of great subsidence from some cause; and the coral reefs for some reason have manifestly kept themselves at the surface in spite of it. ${ }^{2}$

3. If superficially acting causes are insufficient, we are led to look deeper, to the sources of the earth's energies, or its interior

${ }^{2}$ In the Arctic seas, going north from the Scandinavian plateaur, the water deepens north of the latitude of Iceland, between Greenland and Spitzbergen, to 2000 fathoms, and farther north to 2650 fathoms, in the latitude nearly of Greenwich; and it is probable that the 2000-fathom area extends over the region of the North Pole. The continents of Europe (with Asia probably) and North America are proved by the shallow soundings over the adjoining Arctic seas and the islands or emerged land, to extend to about $822^{\circ} \mathrm{N}$., which is about 450 miles from the Pole.

2 The migrations from South America alluded to in note 2 on page 358 , proving an elevation of 2000 feet to make it possible, prove also that a large part of the West India seas afterzuard suffered subsidence in the Quaternary. How far the Bahama and Florida region participated in the subsidence is not krown. That it did not participate in it has not been proved. 
agencies of development, to which the comprehensive system in its structure and physiognomy points. Whatever there is of system in the greater feature-lines, whether marked in troughs or in mountain chains, or island ranges, must come primarily from systematic work within. The work may have been manifested in long lines of flexures or fractures as steps in the process, but the condition; which gave directions to the lines left them subject to local causes of variation, and between the two agencies, the resulting physiognomy has been evolved.

We have from the Pacific area one observation of a volcanic nature bearing on the comprehensiveness of the system of feature lines in the oceans, and although I have already referred to it, I here reproduce the facts for use in this place.

If the ranges of volcanic islands were, in their origin, lines of fissures as a result of comprehensive movements, the lines should continue to be the courses of planes of weakness in the earth's crust. The New Zealand line, including the Kermadec Islands and the Tongan group, has been pointed to as one of these lines, and one of great prominence, since it is the chie north-eastward range of the broad Pacific, and nearly axial to the ocean. The series of volcanoes along the axis of New Zealand is in the same line. It was noticed, at the Tarawera eruption of 1883 , that four or five days after the outbreak, and three after it had subsided, White Island, in the Bay of Plenty, at the north end of the New Zealand series, became unusually active ; and two months later there was a violent eruption in the Tonga group, on the Island of Niuafou. The close relation in time of the latter to the New Zealand eruption is referred to by Mr. C. Trotter, in NATURE of December 7, $1886 .{ }^{1}$ May it not be that these disturbances were due to a slight shifting or movement along a series of old planes of fractures, taking place successively from south to north; and, hence, that even now changes of level may take place through the same comprehensive cause that determined the existence of the earth's feature lines ? Owing to the long distance of the Tonga group from New Zealand an affirmative reply to the question cannot be positively made. But there is probability enough to give great interest to this branch of geological enquiry. JAMES D. DANA.

\section{SOCIETIES AND ACADEMIES. PARIS.}

Academy of Sciences, July 28.-M. Hermite in the chair. -Aquatic locomotion studied by photo-chronography, by M. Marey. The author has made similar investigations on animal locomotion to those of Mr. Muybridge, but with different apparatus. A single camera, the sensitive plate of which takes the form of an endless band moving past the focus of the lens, has been used in the investigations, and appears to possess many advantages over the multiple camera system. The contractions and dilatations of the body of the medusa, the undulations of the lateral fins of the ray, and the rapid movements of the dorsal fin of the Hippocampus (sea-horse), have all been analyzed, and in the zoëtrope the successive photographs appear to have reproduced the motions to perfection. - Observations, orbit, and ephemeris of the comet discovered by $M$. Coggia ( 6 I 890$)$ at Marseilles Observatory, by M. Stephan.On the observation of the annular eclipse of the sun of June $I 7$, by M. A. de la Baume Pluvinel. A detailed description of the instruments employed by the author for his observations in Canea (Island of Crete) is given. As previously noted (NATURE, July (o), the results give further support to the view that the oxygen absorption bands in the solar spectrum are of telluric origin.-Observations of the minor planet recently discovered by $\mathrm{M}$. Charlois (297), made with the coudé equatorial and the Foucault telescope at Algiers Observatory, by MM. Rambaud and Sy. Some observations of position and comparison stars are given.-Observations of Coggia's comet, made with the great equatorial of Bordeaux Observatory, by MM. Picart and Courty. - Observations of the same comet made at Paris Observatory, by Mdlle. D. Klumpke.-On a new method of exposition of the theory of theta functions, and on an elementary theorem relative to hyperelliptic functions of the first dimension, by M, F. Caspary. It is shown that the fifteen hyperelliptic functions of the first dimension are proportional to the fifteen elements of an orthogonal system.-Earthquakes in Madagascar, by:M. R. P. Colin, Director of the Antananarivo Observatory. The five earth-tremors observed this year appear to have had an influence on the azimuth error of the transit

'American Journal of Science, III., xxxiii., 3тг.

NO. IO84, VOL. 42$]$ instrument. - On the water of crystallization of neutral sulphate of alumina; analysis of a natural product, by M. P. MargueriteDelacharlonny. The analysis of two samples of definitely crystallized natural sulphate of alumina from Bolivia supports the author's previous conclusion that its formula should be written with sixteen instead of eighteen molecules of water of crystallization. - On the optical rotatory power of camphor in solution in various oils, by $M$. P. Chabot. The author finds that the rotation produced by the solutions is sensibly proportional to their strengths, and that, after allowing for the slight rotation due to the oil, the calculated molecular rotatory power of camphor is practically constant.-On the malonates of lithia and on the malonate of silver, by M. G. Massol. Some experiments on the heats of formation are given.--Researches on the optical dispersion of organic compounds; fatty acids, by MM. $\mathrm{Ph}$. Barbier and L. Roux. The authors have examined the normal fatty acids from formic to pelargonic as well as isobutyric and isovaleric acids, and find that the specific dispersive powers increase with the molecular complexity, and that those of isomeric acids are practically equal, though the normal acids have slightly the higher value.- On the presence of furfural in commercial alcohols, by M. L. Lindet.-Contribution to the study of artificial musk, by M. Albert Baur.-Mode of action of bacterial secretions on the vasomotor nervous system; connection between these phenomena and diapedesis, by MM. A. Charrin and E. Gley.-Does hæmoglobin exist in the blood as a homogeneous substance?, by M. Christian Bohr. - On the identity of structure of the central nervous system of Pelecypoda and other Mollusca, by M. Paul Pelseneer.-On the bathymetric distribution of the deep-sea Brachiopods collected in the Travailleur and Talisman expeditions, by MM. P. Fischer and D. P. CEhlert.-On the position in the plant of the compounds which produce the sulphuretted essential oils of the Cruciferæ, by M. Léon Guignard.

BOOKS, PAMPHLETS, and SERIALS RECEIVED.

The Theory of Light: T. Preston (Macmillan).-Weather Forecasting of the British Isles: Captain H. Toynbee (Stanford).--Psychology : M. Mahe (Longmans).-Geometrical Conics, Part $x:$ Rev. J. J. Milne and R. F. Davis (Macmillan). - Text-book of Mechanics : T. W. Wright (New York, Van Nostrand).-Sap: Does it rise from the Roots? J. A. Reeves (Kenning). - The History of Federal and State Aid to Higher Education in the United States: Dr. F. W. Blackmar (Washington).-Proceedings of the Department of Superintendence of the National Educational Association at its Meeting in Washington, March 6 to 8, x889 (Washington).

\section{CONTENTS.}

PAGE

The History of Botany. By D. H. S. . . . . . 337

A Text-book of Physiological and Pathological

Chemistry .............. 338 The Advancement of Science . . . . . . 339

Our Book Shelf:-

Salet, Girard, and Pabst : "Agenda du Chimiste."A. E. T.

Williams : "The Philosophy of Clothing".... 340

\section{Letters to the Editor:-}

The Zoological Affinities of Heliopora cerulea, Bl.W. Saville-Kent

Chambers's "Hand-book of Astronomy."-E. W. Maunder; The Reviewer . . . . . . . 34I

Gregory's Series.-R. Chartres . . . . . . . 34I

The Perseid Meteor Shower. -W. F. Denning : 342 Comparison of the Spectra of Nebulæ and Stars of Groups I. and II. with those of Comets and Auroræ. I. By Prof. J. Norman Lockyer, F.R.S. On the Study of Earthquakes in Great Britain. (Illustrated.) By Charles Davison $\dot{A}$. - illusThe Horned Dinosaurs of the United States. (Illustreted Beting of the British Association at Leeds - 349

Our Astronomical Column:-

Objects for the Spectroscope.-A. Fowler . . . . . 354

Catalogue of Red Stars . . . . . . . . . 354

Ancient Eclipses . . . . . . . . . . . . 354

Coggia's Comet (b I89o) . . . . . . . . . 355

The Institution of Mechanical Engineers $\quad 355$

On the Origin of the Deep Troughs of the Oceanic

Depression: Are any of Volcanic Origin? By

Prof. James D. Dana . . . . . . . . . . . 357

Societies and Academies : . . . . . 360

Books, Pamphlets, and Serials Received . . . 360 